\title{
Multicomponent Polyanions. X. A Stopped-flow Study of the Kinetics of the Decomposition of Pentamolybdodiphosphates and Heptamolybdates in Alkaline 3.0 $\mathrm{M} \mathrm{Na}\left(\mathrm{ClO}_{4}\right)$
}

\author{
ROLF MELLSTRÖM and NILS INGRI
}

Department of Inorganic Cemistry, University of Umeå, S-901 87 Umeå, Sweden

\begin{abstract}
The decomposition of the aqueous pentamolybdodiphosphates, $\mathrm{Mo}_{5} \mathrm{P}_{2} \mathrm{O}_{23}{ }^{6-}, \mathrm{HMo}_{5} \mathrm{P}_{2} \mathrm{O}_{23}{ }^{5-}$, and $\mathrm{H}_{2} \mathrm{Mo}_{5} \mathrm{P}_{2} \mathrm{O}_{23}{ }^{4-}$, in alkaline $3.0 \mathrm{M} \mathrm{Na}\left(\mathrm{ClO}_{4}\right)$, has been studied at $25^{\circ} \mathrm{C}$ by using spectrophotometric stopped-flow measurements. It was found that the protonized species were instantaneously neutralized to $\mathrm{Mo}_{5} \mathrm{P}_{2} \mathrm{O}_{23}{ }^{6-}$ and that the decomposition of $\mathrm{Mo}_{5} \mathrm{P}_{2} \mathrm{O}_{23}{ }^{6-}$ followed the rate equation - $\mathrm{d}\left[\mathrm{Mo}_{5} \mathrm{P}_{2} \mathrm{O}_{23}{ }^{6-}\right] / \mathrm{d} t=k\left[\mathrm{Mo}_{5} \mathrm{P}_{2} \mathrm{O}_{23}{ }^{6-}\right]$ $\left[\mathrm{OH}^{-}\right]$, where the rate constant $k$ was determined to be $16.7 \pm 0.9 \mathrm{M}^{-1} \mathrm{~s}^{-1}$. This result strongly supports emf-equilibrium measurements which suggest the mentioned protonized series. Equilibrium solutions corresponding to the heptamolybdates $\mathrm{Mo}_{7} \mathrm{O}_{24}{ }^{6-}$, $\mathrm{HMo}_{7} \mathrm{O}_{24}{ }^{5-}$, $\mathrm{H}_{2} \mathrm{Mo}_{7} \mathrm{O}_{24}^{4-}$, and $\mathrm{H}_{3} \mathrm{Mo}_{7} \mathrm{O}_{24}{ }^{3-}$ have also been studied. The proton series could not be verified through the measurements. However, for $\mathrm{Mo}_{7} \mathrm{O}_{24}{ }^{6-}$ a bimolecular rate constant could be determined to be $13000 \pm 1300 \mathrm{M}^{-1} \mathrm{~s}^{-1}$. At compositions corresponding to the protonized species no instantaneous neutralization could be observed. Instead, a rather slow reaction occurred. Whether this reaction is caused by silicate impurities or by an octamolybdate could not be decided. However, a bimolecular rate constant with the value of $260 \pm 30 \mathrm{M}^{-1} \mathrm{~s}^{-1}$ was determined. Some preliminary observations of the protonization reactions are also reported.
\end{abstract}

In recent investigations ${ }^{1-3}$ the three component equilibria $p \mathrm{H}^{+}+q \mathrm{MoO}_{4}^{2-}+r \mathrm{HPO}_{4}{ }^{2-} \rightleftharpoons\left(\mathrm{H}^{+}\right)_{p-}$ $\left(\mathrm{MoO}_{4}{ }^{2-}\right)_{q}\left(\mathrm{HPO}_{4}{ }^{2-}\right)$, were studied using emf methods $\left(25^{\circ} \mathrm{C}, 3.0 \mathrm{M} \mathrm{Na}\left(\mathrm{ClO}_{4}\right)\right.$ medium). In the range $1.5<-\log \left[\mathrm{H}^{+}\right]<9$ and with phosphate ions in excess $(M o / P<2.5)$ it was found that the main ternary complexes formed are $\mathrm{Mo}_{5} \mathrm{P}_{2} \mathrm{O}_{23}{ }^{6-}$, $\mathrm{HMO}_{5} \mathrm{P}_{2} \mathrm{O}_{23}{ }^{5-}$, and $\mathrm{H}_{2} \mathrm{Mo}_{5} \mathrm{P}_{2} \mathrm{O}_{23}{ }^{4-}$ (coordinated sodium ions and water have been omitted in the formula). At higher $M o / P$ ratios

Acta Chem. Scand. A 28 (1974) No. 7 also protonized enneamolybdomonophosphates are present and the species $\mathrm{H}_{3} \mathrm{Mo}_{9} \mathrm{PO}_{34}{ }^{6}, \mathrm{H}_{4^{-}}$$\mathrm{Mo}_{9} \mathrm{PO}_{34}{ }^{5-}, \mathrm{H}_{5} \mathrm{Mo}_{9} \mathrm{PO}_{34}{ }^{4-}$, and $\mathrm{H}_{6} \mathrm{Mo}_{9} \mathrm{PO}_{34}{ }^{3-}$ have been proposed. At these higher $M o / P$ ratios considerable amounts of binary $\mathbf{H}^{+}$. $\mathrm{MoO}_{4}^{2-}$ complexes are also present, and the most probable species may be $\mathrm{Mo}_{7} \mathrm{O}_{24}{ }^{6-}, \mathrm{HMo}_{7}$ $\mathrm{O}_{24}{ }^{5-}, \mathrm{H}_{2} \mathrm{Mo}_{7} \mathrm{O}_{24}{ }^{4-}, \mathrm{H}_{3} \mathrm{Mo}_{7} \mathrm{O}_{24}{ }^{3-}, \mathrm{HMoO}_{4}{ }^{-}$, and $\mathrm{H}_{2} \mathrm{MoO}_{4} \cdot{ }^{4,5}$ However, instead of or in addition to the protonized heptamolybdate series different octamolybdates may also be present. From emf-measurements alone it is very difficult to make a decision between these possibilities, and support from other measurements is needed.

Exact knowledge of the mechanism for formation and decomposition of all the ions mentioned is of greatest importance. It is a difficult task to obtain a complete picture directly. Many different experimental approaches are surely necessary. A suitable starting point would be a spectrophotometric stopped-flow study. The aim of the present work is to study the decomposition of the above mentioned pentamolybdodiphosphates and the heptamolybdates in alkaline 3.0 M Na(ClO $)_{4}$. In this way we hope to be able to further confirm the proposed protonized series. Some preliminary kinetic measurements will also be performed on the formation reactions for these ions. Concerning the enneamolybdomonophosphates their decomposition has not yet been completely studied but will, as we hope, be presented in a forthcoming paper.

Previous studies. Lagrange and Schwing ${ }^{\circ}$ have studied the decomposition of $\mathrm{Mo}_{7} \mathrm{O}_{24}{ }^{6-}$ in four different alkaline $\mathrm{NaCl}$ media of total 
concentrations $1,2,3$, and $4 \mathrm{M}$ at $15,25,35$, and $45^{\circ} \mathrm{C}$. Their experiments showed that the reaction is of first order with respect to each of the reagents $\mathrm{Mo}_{7} \mathrm{O}_{24}{ }^{6-}$ and $\mathrm{OH}^{-}$. It was also found that the logarithm of the rate constant is a decreasing linear function of the medium concentration. For the rate constant in $3.0 \mathrm{M} \mathrm{NaCl}$ and at $25^{\circ} \mathrm{C}$ they determined the value to be $8500 \pm 300 \mathrm{M}^{-1} \mathrm{~s}^{-1}$. Schwarzenbach and Meier ${ }^{7}$ have studied condensation reactions of molybdates in aqueous solutions with a continuous flow apparatus. They concluded that the condensation reactions are very fast and they estimated that eventual bimolecular reactions must run with the rate constant of the order of at least $10^{5} \mathrm{M}^{-1} \mathrm{~s}^{-1}$. For low $\mathrm{MoO}_{4}{ }^{2-}$ concentrations $\left(<2 \times 10^{-4} \mathrm{M}\right)$ they were able to measure the protonation of $\mathrm{MoO}_{4}^{2-}$ ions before condensation reactions occurred.

No kinetic studies of pentamolybdodiphosphates seem to have been carried out.

\section{EXPERIMENTAL}

The present work has been carried out in close connection to emf work by Pettersson. ${ }^{1-8}$ The chemicals used, the preparation of solutions and the measurements of $-\log \left[\mathrm{H}^{+}\right]$have been described earlier. ${ }^{1}$

The stopped-flow measurements were carried out using a Durrum stopped-flow spectrophotometer type 13000 and the cuvette used had a length of $0.2 \mathrm{~cm}$ (calibrated to $0.193 \mathrm{~cm}$ ). The transmittance-time data were recorded on a photographic film and the oscilloscope was equipped with a special measuring screen grid. The arrangement with the grid made it possible to measure out transmittance-time points with good accuracy. It also allowed a comparison between different films. Another advantage with the screen grid is that it is finer than the standard grid, and thereby more points of one film can be measured. During the reaction runs the cathodic ray of the oscilloscope was directly recorded on the film without using the storage screen.

Some complementary absorbance measurements and the determinations of molar absorption coefficients were made on a Bausch and Lomb Spectronic 505 spectrophotometer and a cuvette with a path-length of $0.1 \mathrm{~cm}$ (QS. HELLMA) was used.

\section{Method}

Equal volumes of an equilibrium solution and a sodium hydroxide solution were rapidly (within less than $10 \mathrm{~ms}$ ) mixed in the stopped- flow spectrophotometer. The temperature was kept at $25 \pm 0.1^{\circ} \mathrm{C}$ and a background medium of 3.0 $\mathrm{M} \mathrm{Na}\left(\mathrm{ClO}_{4}\right)$ was used. In the equilibrium solution the total concentrations of molyb. denum, phosphorus, and protons over the zero level $\left(\mathrm{MOO}_{4}{ }^{2-}, \mathrm{HPO}_{4}{ }^{2-}\right.$, and $\left.\mathrm{H}_{2} \mathrm{O}\right)$ were exactly known. On mixing it was assumed that the free protons and the protons in the protonized species $\mathrm{HPO}_{4}{ }^{2-}, \mathrm{H}_{2} \mathrm{PO}_{4}-, \mathrm{H}_{3} \mathrm{PO}_{4}, \mathrm{HMo}_{5} \mathrm{P}_{2} \mathrm{O}_{23}{ }^{5-}$, $\mathrm{H}_{2} \mathrm{Mo}_{5} \mathrm{P}_{2} \mathrm{O}_{23}{ }^{4-}$, $\mathrm{HMO}_{7} \mathrm{O}_{24}{ }^{3-}, \mathrm{H}_{2} \mathrm{Mo}_{7} \mathrm{O}_{24}{ }^{4-}, \mathrm{H}_{3} \mathrm{Mo}_{7}-$ $\mathrm{O}_{24}{ }^{3-}$, $\mathrm{HMOO}_{4}$ - and $\mathrm{H}_{2} \mathrm{MoO}_{4}$, were instantaneously neutralized by the excess of $\mathrm{OH}^{-}$. Hence at the start of the reaction $(t=0)$ we have in the molybdophosphate case the species $\mathrm{Mo}_{5} \mathrm{P}_{2} \mathrm{O}_{23}{ }^{6-}$, $\mathrm{PO}_{4}{ }^{3-}, \mathrm{MoO}_{4}{ }^{2-}, \mathrm{OH}^{-}$, and in the heptamolybdate case the species $\mathrm{Mo}_{7} \mathrm{O}_{24}{ }^{6-}, \mathrm{MoO}_{4}{ }^{2-}, \mathrm{OH}^{-}$. By using available equilibrium constants the con. centrations of these species after mixing were calculated. The total $\mathrm{OH}^{-}$concentration was adjusted for the above mentioned proton reactions. Thus the overall reactions that will be studied are:

$$
\begin{aligned}
& \mathrm{Mo}_{3} \mathrm{P}_{2} \mathrm{O}_{23}{ }^{8-}+10 \mathrm{OH}^{-} \rightarrow 5 \mathrm{MoO}_{4}{ }^{2-}+2 \mathrm{PO}_{4}{ }^{3-}+ \\
& 5 \mathrm{H}_{2} \mathrm{O}^{-} \\
& \mathrm{Mo}_{7} \mathrm{O}_{24}{ }^{6-}+8 \mathrm{OH}^{-} \rightarrow 7 \mathrm{MoO}_{4}{ }^{2-}+4 \mathrm{H}_{2} \mathrm{O}
\end{aligned}
$$

The rate of decomposition was followed on an oscilloscope screen and recorded on a photographic film. From each film a suitable number of transmittance-time $(T-t)$ data were picked out (mostly about 20 pairs). These data together with the species concentrations, $c_{i}$, at $t=0$, are the primary data of each experiment. To make the measurements as accurate as possible and also to follow the different species concentra-

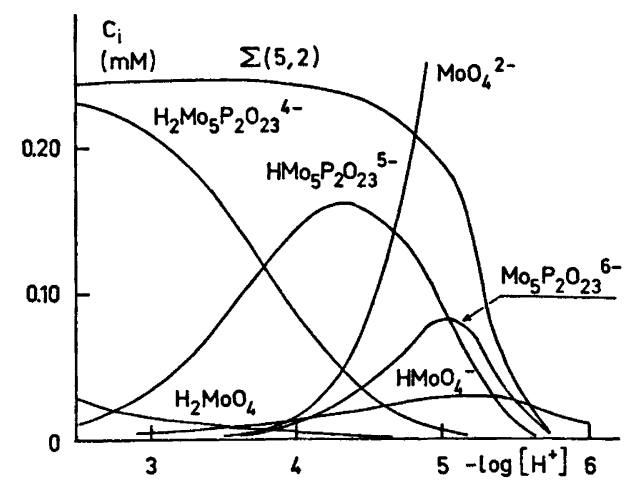

Fig. 1. Distribution diagram for $[\mathrm{Mo}]_{\text {tot }}=1.25$ $\mathrm{mM}$ and $[\mathrm{P}]_{\text {tot }}=1.00 \mathrm{mM}$ showing concentrations $\left(c_{i}\right)$ of complexes containing molybdenum, as a function of $-\log \left[\mathrm{H}^{+}\right]$. In the calculation the binary $\mathrm{H}^{+}-\mathrm{MoO}_{4}^{2-}$ species and formation constants proposed by Sasaki and Sillén, and the ternary $\mathrm{H}^{+}-\mathrm{MoO}_{4}^{2-}-\mathrm{HPO}_{4}^{2-}$ species and formation constants proposed by Pettersson ${ }^{1}$ were used.

Acta Chem. Scand. A 28 (1974) No. 7 


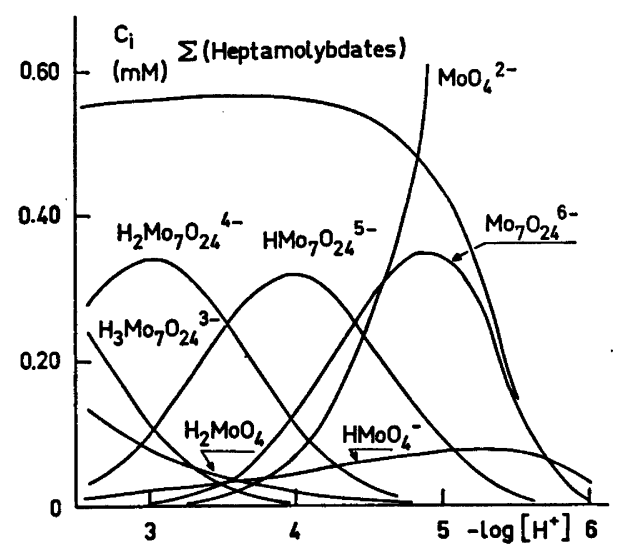

Fig. 2. Distribution of $\mathrm{H}^{+}-\mathrm{MoO}_{4}^{2-}$ complexes as a function of $-\log \left[\mathrm{H}^{+}\right]$for $[\mathrm{Mo}]_{\text {tot }}=4.00$ $\mathrm{mM}$. In the calculation species and formation constants proposed by Sasaki and Sillén ${ }^{4}$ were used.

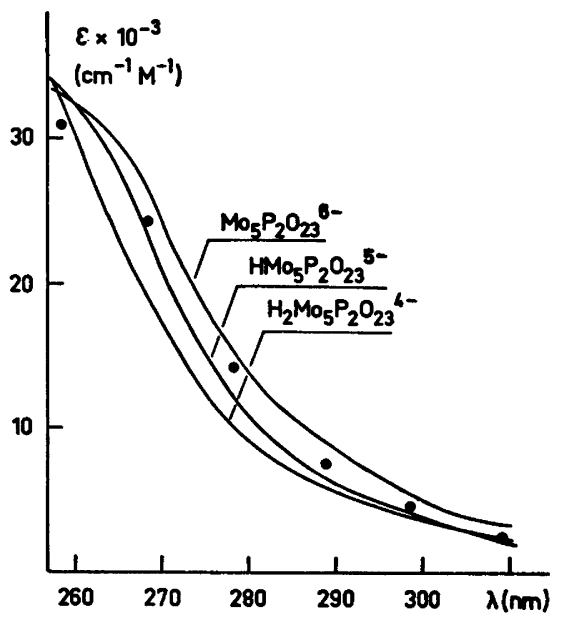

Fig. 3. Molar absorption coefficient curves for the pentamolybdodiphosphate complexes. The values have been taken from a work by Lyhamn.8 "Best" values obtained at the six wavelengths studied in this work are plotted with the symbol 0 .

tions, we have performed the measurements at a number of suitable wavelengths.

Species distributions and molar absorption coefficients. The distributions of molybdophosphate and heptamolybdate complexes as functions of $-\log \left[\mathrm{H}^{+}\right]$are given in Figs. 1 and 2. The total concentrations have been chosen so that the diagrams give a representative picture of the concentration conditions during our stopped-flow experiments.

Acta Chem. Scand. A 28 (1974) No. 7

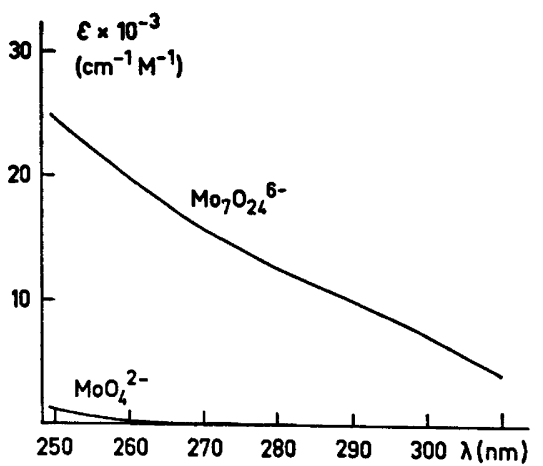

Fig. 4. Molar absorption coefficient curves for $\mathrm{MoO}_{4}{ }^{2-}$ and $\mathrm{Mo}_{7} \mathrm{O}_{24}{ }^{6-}$. The values have been taken from a work by Lyhamn. ${ }^{8}$

Curves of molar absorption coefficients of the actual species in the UV range $250-310 \mathrm{~nm}$ are shown in Figs. 3 and 4. The values have been taken from a work by Lyhamn. ${ }^{8}$ None of the phosphate species absorbs in the wavelength range studied.

Choice of wavelengths and concentrations. The wavelength range was chosen to be $260-310$ $\mathrm{nm}$. In this range the molar absorption coefficient of $\mathrm{MoO}_{4}{ }^{2-}$ is negligible in comparison to the high molar absorption coefficient values of the molybdophosphates and heptamolybdates (see Figs. 3 and 4). For the pentamolybdodiphosphate measurements the wavelengths 259 , $269,279,289,299$, and $309 \mathrm{~nm}$ were used. Due to the high molar absorption coefficients, the concentrations of studied species have to be relatively low. By using the smallest cuvette length available for stopped-flow measurements $(0.2$ $\mathrm{cm})$ the total concentrations of molybdenum could be held at $1-4 \mathrm{mM}$ (before mixing).

Treatment of experimental data. The relation between measured transmittance, $T$, and concentrations, $c_{i}$, of light absorbing species is given by Lambert-Beers law; $A=-\log T=l \sum \varepsilon_{i} c_{i}$, where $A$ is the absorbance, $\varepsilon_{i}$ the molar absorption coefficient of the $i$ :th species, and $l$ is the cuvette length. Now, if the species concentrations, at $t=0$, are exactly known or estimated rate constants and molar absorption coefficients are available, a calculated absorbance value $A_{\text {calc }}$ can be obtained for each measured $T-t$ value. Using the least squares principle the rate constant, $k$, is then determined so that the error squares sum $U=\sum\left(A_{\mathrm{calc}}-A\right)^{2}$ is minimized. A Letagrop version for this calculation has been worked out.'

\section{CALCULATIONS AND RESULTS}

Decomposition of $\mathrm{Mo}_{5} \mathrm{P}_{2} \mathrm{O}_{23}{ }^{6}$. It was found that the decomposition of $\mathrm{Mo}_{5} \mathrm{P}_{2} \mathrm{O}_{23}{ }^{6}$ - obeyed 
the rate expression $-\mathrm{d}\left[\mathrm{Mo}_{5} \mathrm{P}_{2} \mathrm{O}_{23}{ }^{6}-\right] / \mathrm{d} t=k\left[\mathrm{Mo}_{5}\right.$ $\left.\mathrm{P}_{2} \mathrm{O}_{23}{ }^{6}\right]\left[\mathrm{OH}^{-}\right]$, where $k$ is the rate constant. The reaction was studied for several combinations of $\left[\mathrm{Mo}_{5} \mathrm{P}_{2} \mathrm{O}_{23}{ }^{6-}\right]$ and $\left[\mathrm{OH}^{-}\right]$, and three series of experiments were carried out. In two of the series $[\mathrm{Mo}]_{\text {tot }}$ and $[\mathrm{P}]_{\text {tot }}$ were $2.50 \mathrm{mM}$ and $1.50 \mathrm{mM}$, respectively. In the third series the concentrations were $1.25 \mathrm{mM}$ and $1.00 \mathrm{mM}$. (The values given refer to concentrations before mixing). Within each of the series the $-\log \left[\mathrm{H}^{+}\right]$ values in the equilibrium solutions have been chosen within the limits $2.0<-\log \left[\mathrm{H}^{+}\right]<5.5$. The choice has been made so that all the three species $\mathrm{Mo}_{5} \mathrm{P}_{2} \mathrm{O}_{23}{ }^{6}-, \mathrm{HMo}_{5} \mathrm{P}_{2} \mathrm{O}_{23}{ }^{5-}$, and $\mathrm{H}_{2} \mathrm{Mo}_{5}$ $\mathrm{P}_{2} \mathrm{O}_{23}{ }^{4-}$ are well represented in the final data material. The total $\mathrm{OH}^{-}$concentrations used in the three series were $98.60 \mathrm{mM}, 199.7 \mathrm{mM}$, and $150.2 \mathrm{mM}$ (before mixing). With such an excess of $\mathrm{OH}^{-}$ions it was found that for each solution investigated, the reaction rate became monomolecular with respect to $\mathrm{Mo}_{5} \mathrm{P}_{2} \mathrm{O}_{23}{ }^{6}-$. A monomolecular rate constant, $k_{\text {obs }}$, was calculated for each solution and then, by using the relation $k_{\text {obs }}=k\left[\mathrm{OH}^{-}\right]$, a bimolecular rate constant, $k$, was determined. Examining these values we found that the $k$ values were independent of both the total concentrations and the wavelengths used. A mean value of $k$ for all data gave $k=16.7 \pm 0.9 \mathrm{M}^{-1} \mathrm{~s}^{-1}$ (based on 80 different measurements).

In another Letagrop calculation a variation of $k$ together with the molar absorption coefficient of $\mathrm{Mo}_{6} \mathrm{P}_{2} \mathrm{O}_{23}{ }^{6-}$ at the six wavelengths studied was made. The calculation gave $k=$ $16.8 \pm 0.6 \mathrm{M}^{-1} \mathrm{~s}^{-1}$ and the molar absorption coefficients $30.4 \pm 1.3,24.6 \pm 0.9,14.1 \pm 0.4,7.4 \pm$ $0.5,4.3 \pm 0.1$, and $2.4 \pm 0.1\left(10^{-8} \mathrm{~cm}^{-1} \mathrm{M}^{-1}\right)$ at $259,269,279,289,299$, and $309 \mathrm{~nm}$, respectively. A comparison between these values and those obtained by Lyhamn ${ }^{8}$ is given in Fig. 3. The agreement is that expected from the experimental accuracy of the measurements.

The main conclusion of the present measurements is that the decomposition rate constant is independent of whether the original equilib. rium solution contains $\mathrm{Mo}_{5} \mathrm{P}_{2} \mathrm{O}_{23}{ }^{6-}, \mathrm{HMO}_{5} \mathrm{P}_{2}$ $\mathrm{O}_{23}{ }^{5-}$ or $\mathrm{H}_{2} \mathrm{Mo}_{5} \mathrm{P}_{2} \mathrm{O}_{23}{ }^{4-}$. This strongly verifies the results from the equilibrium analyses and provides good support for the existence of a series of protonized pentamolybdodiphosphate anions.

Decomposition of $\mathrm{Mo}_{7} \mathrm{O}_{24}{ }^{6-}$. A number of equilibrium solutions were studied with $[\mathrm{Mo}]_{\text {tot }}$ being $4.00 \mathrm{mM}$ and with different $Z$-values covering the range $0<Z<1.5 . Z$ is the average number of $\mathrm{H}^{+}$bound per $\mathrm{MoO}_{4}{ }^{2-}$. The $\mathrm{OH}^{-}$ concentration used was $8.91 \mathrm{mM}$. The values given refer to concentrations before mixing. It was found that as long as the $Z$-values were within the limits $0<Z<0.6$ the rate of the decomposition of $\mathrm{Mo}_{7} \mathrm{O}_{24}{ }^{6}$ - could be written $-\mathrm{d}\left[\mathrm{Mo}_{7} \mathrm{O}_{24}{ }^{6}\right] / \mathrm{d} t=k\left[\mathrm{Mo}_{7} \mathrm{O}_{24}{ }^{6}\right]\left[\mathrm{OH}^{-}\right]$, with $k=$ $13000 \pm 1300 \mathrm{M}^{-1} \mathrm{~s}^{-1}$ (a mean value obtained from seven different experiments). There is a considerable difference between this value and the value obtained by Lagrange and Schwing ${ }^{\circ}$ who reported $8500 \mathrm{M}^{-1} \mathrm{~s}^{-1}$ in $3 \mathrm{M} \mathrm{NaCl}$ at $25^{\circ} \mathrm{C}$. The difference may, however, be due to medium effects. For solutions with higher $Z$-values it was found that an additional comparatively slow decomposition reaction occurred. The contribution from the slow reaction was found to increase when $-\log \left[\mathrm{H}^{+}\right]$was lowered. By making measurements at very high $\mathrm{OH}^{-}$concentrations we were able to study this slow reaction separately. The study was made using solutions with $[\mathrm{Mo}]_{\text {tot }}=1.00 \mathrm{mM}$ and $4.00 \mathrm{mM}$ and in the range $2.6<-\log \left[\mathrm{H}^{+}\right]<4.7$. The $\mathrm{OH}^{-}$concentrations used were $49.67 \mathrm{mM}$ and $99.76 \mathrm{mM}$. In this great excess of $\mathrm{OH}^{-}$the slow reaction could be explained with the rate equation $-\mathrm{d} c /$ $\mathrm{d} t=k c\left[\mathrm{OH}^{-}\right]$, where $c$ is the concentration of an undefined species and $k$ is the rate constant determined to be $260 \pm 30 \mathrm{M}^{-1} \mathrm{~s}^{-1}$. We suspected that the solutions could contain silicate impurities and that the species probably was a molybdosilicate complex. This was partly verified through separate studies where silicate ions were added to the solutions. That the silicate ions did not disturb the pentamolybdodiphosphate studies depended probably on the fact that an excess of phosphate ions was used and that the complex formation between molybdate and phosphate ions is stronger than between molybdate and silicate ions. Instead of a silicomolybdate complex the observed unknown species may be, for instance, an octamolybdate, and thus the measurements do not seem to confirm a protonized heptamolybdate series.

Some preliminary measurements of formation reactions. When molybdate solutions with $\left[\mathrm{MoO}_{4}{ }^{2-}\right]=2.00 \mathrm{mM}$ were rapidly mixed with $\mathrm{H}^{+}$-solutions with concentrations between $10^{-3}$ and $10^{-5} \mathrm{M}$, it was found that the absorbance 
and thus the concentration of the formed heptamolybdates, increased proportionally with the initial $\mathrm{H}^{+}$-concentration. The overall reactions were finished after about $0.1 \mathrm{~s}$. This fast condensation reaction also occurred when $\mathrm{HPO}_{4}{ }^{2-}$ ions were present together with $\mathrm{MoO}_{4}{ }^{2-}$, but in this case it was followed by a slow reaction, which was completed after about $10 \mathrm{~min}$.

Acknowledgements. The English of the present paper has been corrected by Dr. Michael Sharp. The authors wish to thank Fil.lic. Lage Pettersson for valuable help and discussions. The work forms part of a program financially supported by the Swedish Natural Science Research Council.

\section{REFERENCES}

1. Pettersson, L. Acta Chem. Scand. 25 (1971) 1959.

2. Pettersson, L., Andersson, I., Lyhamn, L. and Ingri, N. Trans. Roy. Inst. Technol., Stockholm 1972, No. 256.

3. Pettersson, L. Chem. Scr. In press.

4. Sasaki, Y. and Sillén, L. G. Acta Chem. Scand. 18 (1964) 1014.

5. Sasaki, Y. and Sillén, L. G. Ark. Kemi 29 (1968) 253.

6. Lagrange, P. and Schwing, J. P. Bull. Soc. Chim. Fr. (1970) 1340.

7. Schwarzenbach, G. and Meier, J. J. Inorg. Nucl. Chem. 8 (1958) 302.

8. Lyhamn, L. To be published.

9. Wennerholm, H., Mellström, R., Rehnberg, O. and Ingri, N. Chem. Scr. In press.

Received April 5, 1974. 